\title{
Effects of acute insulin-induced hypoglycaemia on psychomotor function: people with type 1 diabetes are less affected than non-diabetic adults
}

\author{
J. Geddes • I. J. Deary • B. M. Frier
}

Received: 21 January 2008 / Accepted: 19 June 2008 / Published online: 16 August 2008

(C) Springer-Verlag 2008

\begin{abstract}
Aims/hypothesis We examined the effects of acute insulininduced hypoglycaemia on psychomotor function in nondiabetic volunteers and in adults with type 1 diabetes.

Methods Non-diabetic adults $(n=20)$ and adults with type 1 diabetes mellitus $(n=16)$ each underwent a euglycaemichyperinsulinaemic glucose clamp on two separate occasions. Arterialised blood glucose was maintained for $1 \mathrm{~h}$ at either $4.5 \mathrm{mmol} / 1$ (euglycaemia) or $2.5 \mathrm{mmol} / \mathrm{l}$ (hypoglycaemia). During this time participants underwent neuropsychological tests to assess psychomotor function.

Results During hypoglycaemia the non-diabetic participants showed a significant deterioration in the following: (1) four-choice reaction time $(p=0.008)$; (2) grooved pegboard (a test of manual dexterity; $p=0.004$ ); (3) hand steadiness ( $p=0.003$ ); (4) pursuit rotor (a test of fine motor function, attention and coordination; $p=0.018$ ); and (5) test of total body coordination $(p=0.004)$. No significant differences were observed between euglycaemia and hypoglycaemia in hand-grip $(p=0.897)$ and line tracing time $(p=0.480)$ tests. In type 1 diabetes mellitus patients, only four-choice reaction time $(p=0.023)$ and pursuit rotor $(p=0.045)$ were impaired significantly during hypoglycaemia. Conclusions/interpretation Although acute hypoglycaemia caused significant impairment of several psychomotor
\end{abstract}

J. Geddes • B. M. Frier $(\bowtie)$

Department of Diabetes, The Royal Infirmary of Edinburgh,

51 Little France Crescent,

Edinburgh EH16 4SA, UK

e-mail: brian.frier@luht.scot.nhs.uk

I. J. Deary

Department of Psychology, The University of Edinburgh,

Edinburgh, UK functions in non-diabetic adults, a lower magnitude of impairment was observed in those with type 1 diabetes. The mechanism underlying this discrepant effect of hypoglycaemia on psychomotor function remains unknown, but may be related to the difference in sympathoadrenal activation observed between the groups. People with type 1 diabetes may also have had a behavioural advantage of over nondiabetic participants derived from their previous exposure to hypoglycaemia or potentially the disparate results arose from hypoglycaemia-induced cerebral adaptation

Keywords Cognitive function · Hypoglycaemia . Psychomotor tests · Symptoms of hypoglycaemia - Type 1 diabetes

\section{Introduction}

The human brain is dependent on glucose as its main source of energy; deprivation of glucose causes a rapid deterioration in function through the direct effects of neuroglycopenia [1-3]. When arterialised blood glucose falls below $3.0 \mathrm{mmol} / \mathrm{l}$, performance deteriorates in tests requiring attention, concentration and access to long-term memory, as well as the ability to ignore distracting information [4-7]. Responses to the effects of acute hypoglycaemia vary considerably between individuals and several moderators such as glycaemic control $[6,8]$ and intelligence [9] are thought to influence the susceptibility of an individual's cognitive performance. The effect of hypoglycaemia in causing cognitive dysfunction in general is well recognised. Recent studies have focused on how hypoglycaemia affects specific cognitive domains and on the clinical relevance of any cognitive decrement that occurs [10-14]. 
Psychomotor function is an important domain of mental function that has not been systematically studied with respect to the effect of hypoglycaemia. Psychomotor performance encompasses motor strength, hand-eye coordination, balance, dexterity, tracking and other skills. Clearly, this range of motor and psychomotor capabilities is important in many everyday activities. Hand control, strength, and broad and fine visuo-motor coordination play a vital role in driving, work performance and domestic life. During episodes of iatrogenic hypoglycaemia, people with insulin-treated diabetes have frequently reported a deterioration of fine motor skills [15].

Previous studies of cognitive function during hypoglycaemia have occasionally included isolated psychomotor tests, but none have comprehensively explored effects on this domain of psychological function [6, 7, 9]. However, the few studies that have specifically examined the effects of hypoglycaemia on psychomotor function have been limited by using a blood glucose nadir that would not be considered sufficiently low to have a significant effect on cognitive functions [16]. In other studies, a euglycaemia control arm was not incorporated in the study design, resulting in the effects of practice and fatigue being confounded by the experimental manipulation (euglycaemia versus hypoglycaemia) [17]. These problems have been circumvented by the design of the present study, in which several forms of psychomotor function were measured during hypoglycaemia in healthy non-diabetic volunteers and in healthy adults with type 1 diabetes.

\section{Methods}

\section{Participants}

We studied 20 (11 women) non-diabetic adults (median [interquartile range] age 32 [27-35] years) and 16 (8 women) adults with type 1 diabetes. The participants with type 1 diabetes had a median (interquartile range) age of 40 (36-42.8) years, duration of diabetes of $15(6-25)$ years and mean (SD) $\mathrm{HbA}_{1 \mathrm{c}}$ of $8.2(0.6) \%$. No significant difference in age between the two groups was observed. $\mathrm{HbA}_{1 \mathrm{c}}$ was measured by ion exchange HPLC using a haemoglobin testing system (non-diabetic reference range 5.0-6.05\%; Bio-Rad Laboratories, Munich, Germany) and was DCCTaligned. None of the non-diabetic group had any previous medical or family history of diabetes or was taking regular medication (other than the oral contraceptive pill). As microvascular complications have been linked to a decrease in cognitive performance [18], the participants with type 1 diabetes had to have no evidence of microvascular complications, including diabetic retinopathy, peripheral neuropathy or nephropathy, the latter being defined by having a urine albumin/creatinine ratio persistently above the local reference range or serum creatinine greater than $150 \mu \mathrm{mol} / 1$. This, however, may not be representative of all patients with a median duration of diabetes of 15 years. None of the diabetic participants had impaired awareness of hypoglycaemia as assessed by a validated method [19].

\section{Study design and procedure}

The local Medical Research Ethics Committee approved the study and all participants gave their written informed consent. Each participant attended two laboratory sessions, in which either hypoglycaemia (blood glucose $2.5 \mathrm{mmol} / \mathrm{l}$ ) was induced or euglycaemia (blood glucose $4.5 \mathrm{mmol} / \mathrm{l}$ ) was maintained using a modified euglycaemic-hyperinsulinaemic glucose clamp [20], with each session being separated by at least 2 weeks. The participants were not informed which condition was being studied at each visit. On the evening preceding each session participants fasted from 22:00 hours (thereafter consuming only water). The participants with type 1 diabetes administered their usual dose of insulin during the preceding evening, but no subcutaneous insulin was injected on the morning of the session. Studies were postponed if any of the participants with type 1 diabetes developed either symptomatic or biochemical hypoglycaemia (blood glucose $<4.0 \mathrm{mmol} / \mathrm{l}$ ) during the $48 \mathrm{~h}$ before each study. This resulted in one postponement. The mean (SD) fasting arterialised blood glucose in the group with type 1 diabetes was $7.1(1.1) \mathrm{mmol} / \mathrm{l}$ on the mornings of the studies.

A Teflon cannula was inserted into the ante-cubital vein under local anaesthetic ( $2 \%$ lidocaine). This cannula was used to infuse human soluble insulin (Actrapid; Novo Nordisk, Crawley, UK) and $20 \%$ dextrose. A second cannula was inserted in a retrograde direction into a vein on the dorsum of the non-dominant hand, which was wrapped in a heated blanket to 'arterialise' the venous blood [21]. Arterialised blood samples were obtained throughout the study for the measurement of whole-blood glucose at the bedside using a glucose oxidase method (2300 Stat; Yellow Springs Instruments, Yellow Springs, $\mathrm{OH}, \mathrm{USA})$. An infusion of human insulin was started at $1.5 \mathrm{mU} \mathrm{kg}^{-1} \mathrm{~min}^{-1}$, and $20 \%$ glucose solution was infused at a variable rate to achieve the desired blood glucose concentrations. In each study session, the arterialised blood glucose concentration was stabilised at $4.5 \mathrm{mmol} / \mathrm{l}$ (baseline) for a period of $30 \mathrm{~min}$, after which it was either maintained at $4.5 \mathrm{mmol} / \mathrm{l}$ (euglycaemia) or lowered to $2.5 \mathrm{mmol} / 1$ (hypoglycaemia). After attainment of hypoglycaemia, the target glucose concentration was maintained for a further $10 \mathrm{~min}$ before the cognitive testing commenced. At the end of the hypoglycaemic condition, blood glucose was restored to $4.5 \mathrm{mmol} / \mathrm{l}$. Participants consumed a meal after completion of each study session. 
Adrenaline (epinephrine) and noradrenaline (norepinephrine) concentrations were also measured at baseline, at $45 \mathrm{~min}$ into the experimental condition and upon completion of each session.

\section{Cognitive function tests}

Tests of psychomotor function were performed during the study conditions, as described below.

\section{Psychomotor and motor tests}

Four-choice reaction time test Reaction time is measured using a portable device, incorporating a high-contrast LCD display screen at the top with response keys arranged below in a shallow arc (numbered 1, 2, 0, 3, 4) [22]. For fourchoice reaction time, the participants have to press the corresponding key when one of the four digits (1, 2, 3 or 4) appears on the screen. Mean (SD) of the reaction times for correct responses (40 test trials, preceded by 8 practice trials) were recorded.

Grooved pegboard The pegboard is a test of finger and hand dexterity, and is part of the Wisconsin Neuropsychological Test Battery [23]. The participant is presented with a small board consisting of a $5 \times 5$ set of slotted holes angled in different directions. Each of the matching pegs has a ridge along one side, and participants are required to rotate them until they fit into the correct position. Participants complete the test with their dominant hand. The score is the time taken to complete the task.

Tracing test This test assesses visuo-motor spatial ability [24]. Participants are requested to draw a line using a digital pen (Anoto Group, Lund, Sweden) between two narrow parallel lines while avoiding random circles within the two lines. Accuracy is measured as the total number of times a line is crossed or a circle transected. Two scores are obtained, one for speed of completion in time and one for accuracy (errors).

Pursuit rotor This test (Lafayette Instruments, IN, USA) examines hand-eye coordination and fine motor control. A light target rotates around a track (at a rotation speed of $30 \mathrm{rev} / \mathrm{min}$ ) and the participant is required to hold a stylus over the target to track its movement. Performance is measured by the amount of time the participant can keep the stylus on the target (time on target) during $1 \mathrm{~min}$.

Hand steadiness The participant in this test (Lafayette Instruments) is required to place a metal-tipped stylus in nine progressively smaller holes without touching the sides. The stylus is held in position in each of the holes for $10 \mathrm{~s}$.
The impulse counter silently records activation if contact is made. The score is the total number of times the participant has touched the side of the holes for all nine holes.

Static balance This was measured by static posturography via a force platform designed to measure the position and magnitude of the total vertical component of force applied to it [25]. Participants were tested on a firm surface with their eyes open. During the period of measurement (1 min) the movement of the participant's centre of mass was displayed on a computer screen and the corresponding total path length moved by the centre of mass was calculated.

Hand grip A hand dynamometer (Lafayette Instruments) was placed in the participant's dominant hand at their side away from their body. The participant was instructed to squeeze the dynamometer as hard as possible, with no time constraint for time taken to reach maximum grip. The score is the amount (in $\mathrm{kg}$ ) registered at each of the three trials, with the median calculated for that hand.

\section{Other tests}

These were performed as a validation check, to allow comparison of the effects of hypoglycaemia as demonstrated in previous studies in our laboratory [7, 11, 12].

Digit Symbol test This test assesses sustained attention, speed of response and visual scanning [26].

Symptoms of hypoglycaemia The participants scored the presence and intensity of symptoms of hypoglycaemia using the Edinburgh Hypoglycaemia Symptom Scale [1]. Symptoms of hypoglycaemia are classified as autonomic (hunger, palpitations, sweating, tremor), neuroglycopenic (confusion, drowsiness, difficulty concentrating, weakness) and malaise (nausea, headache).

Statistical analyses

A general linear model (repeated measures ANOVA) was used, with order of session (euglycaemia-hypoglycaemia or hypoglycaemia-euglycaemia) as a between-participants factor and condition (euglycaemia or hypoglycaemia) as a within-participant factor (repeated measure). In the full model, including the non-diabetic volunteers and adults with type 1 diabetes, participant group and order of session were between-participants factor with condition as a withinparticipants factor. A $p$ value of less than or equal to 0.05 was considered to be significant. Effect sizes were calculated using $\eta^{2}$. The principal measures of interest were the $\eta^{2}$ 
values representing the proportion of variance in the test scores accounted for by study condition (euglycaemia vs hypoglycaemia). All analyses were performed using SPSS version 12.0 for Windows (SPSS, Chicago, IL, USA).

\section{Results}

Blood glucose

During the hypoglycaemic condition, the mean (SD) blood glucose was $2.59 \mathrm{mmol} / \mathrm{l}(0.11)$ in the non-diabetic group and $2.58 \mathrm{mmol} / \mathrm{l}(0.11)$ in the group with type 1 diabetes. During euglycaemia mean blood glucose concentrations were $4.45 \mathrm{mmol} / \mathrm{l}(0.12)$ and $4.47 \mathrm{mmol} / \mathrm{l}(0.10)$ in the two groups respectively (Figs 1 and 2).

\section{Symptoms}

During hypoglycaemia the scores from the hypoglycaemia symptom questionnaire for autonomic, neuroglycopenic and malaise symptoms were significantly higher $(p<0.001$ for all) in both groups than the scores obtained during euglycaemia.

\section{Catecholamine concentrations}

Plasma concentrations of adrenaline ( $p=0.04)$ (Fig. 3) and noradrenaline $(p=0.006)$ (Fig. 4) were significantly higher during hypoglycaemia $(t=45 \mathrm{~min})$ in the healthy volunteer group than in type 1 diabetes patients. Similar results were found in the hypoglycaemia recovery period (Fig. 3), but all other time-points revealed no difference in the concentration of catecholamines between the groups. Correlations between plasma concentrations of adrenaline and hand steadiness were non-significant for the healthy volunteer $\left(r_{\mathrm{s}}=0.46, p=\right.$ $0.06)$ and for the type 1 diabetes $\left(r_{\mathrm{s}}=0.008, p=0.84\right)$ groups.

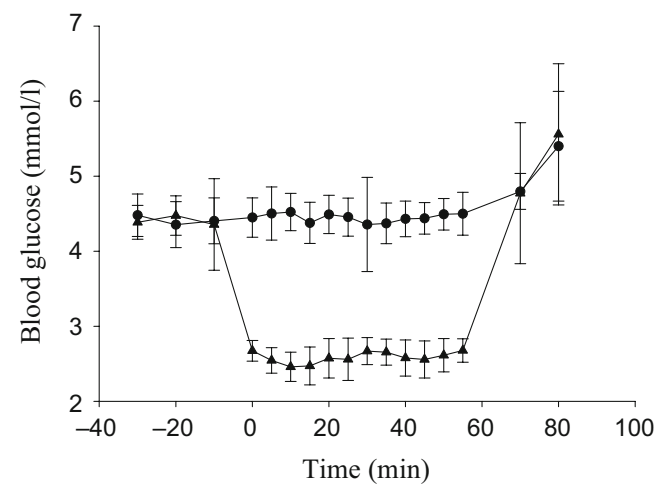

Fig. 1 Mean (SD) blood glucose concentrations at baseline and during study conditions of the euglycaemic (black circles) and hypoglycaemic (black triangles) glucose clamps in the non-diabetic participants

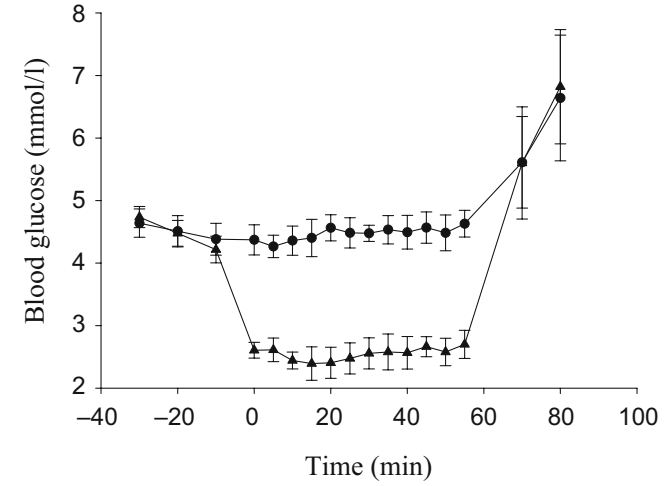

Fig. 2 Mean (SD) blood glucose concentrations at baseline and during study conditions of the euglycaemic (black circles) and hypoglycaemic (black triangles) glucose clamps in the participants with type 1 diabetes

\section{Digit Symbol tests}

The mean (SD) score of the Digit Symbol test deteriorated from 92.7 (12.6) during euglycaemia to 82.5 (9.7) during hypoglycaemia $\left(p<0.001, \eta^{2}=0.624\right)$ in the non-diabetic group and from 81.4 (22.6) to 73.3 (21.6) respectively $\left(p<0.007, \eta^{2}=0.445\right)$ in the group with type 1 diabetes. These findings confirm that the hypoglycaemic intervention had the expected effects comparable to previous studies of similar design $[7,11,12]$.

Psychomotor and motor function tests

The results of mean (SD) and $\eta^{2}$ values of the psychomotor function test scores for both groups during euglycaemia and hypoglycaemia are shown in Table 1. The interaction between glycaemic status and group (healthy controls or type 1 diabetes patients) was then also examined (Table 1). Statistical analysis confirmed that no significant order effects had occurred for any of the outcome variables of the study.

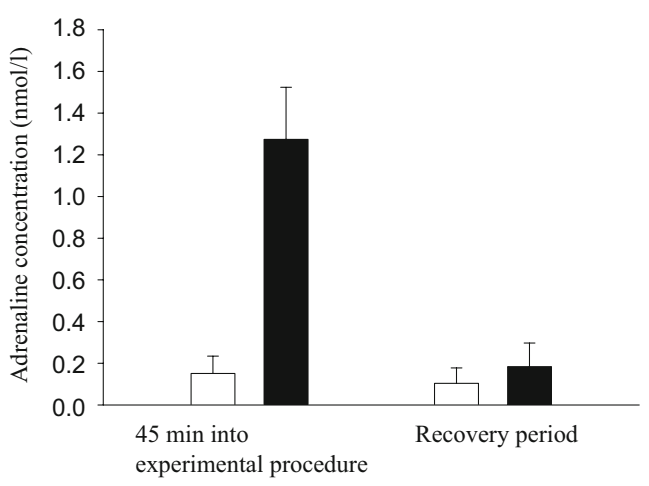

Fig. 3 Mean (SD) plasma adrenaline concentrations during study condition and recovery in healthy volunteers (black bars) and people with type 1 diabetes (white bars) 


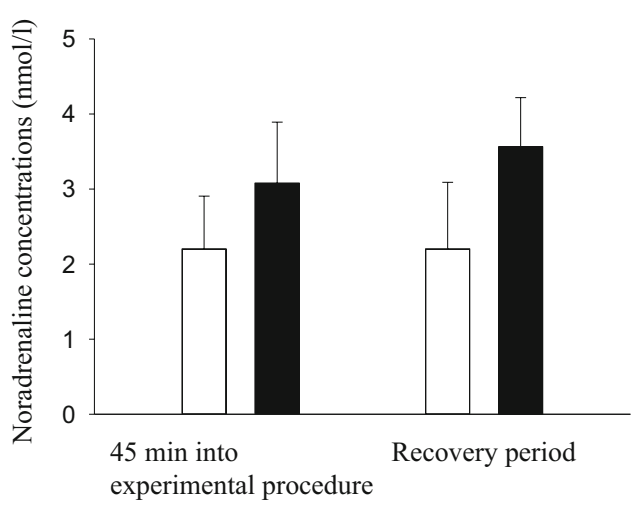

Fig. 4 Mean (SD) plasma noradrenaline concentrations during study condition and recovery in healthy volunteers (black bars) and people with type 1 diabetes (white bars)

Four-choice reaction time

Acute hypoglycaemia caused a significant increase in mean four-choice reaction times, both in the non-diabetic $(p=$ $\left.0.008, \eta^{2}=0.36\right)$ and in the type 1 diabetes $\left(p=0.02, \eta^{2}=\right.$ $0.34)$ groups. The interaction between glycaemic state and participant group (hereafter termed the glycaemia $\times$ group interaction) was not significant $(p=0.76)$.

\section{Grooved pegboard}

In the test of hand dexterity, acute hypoglycaemia caused a significant increase in the time taken to complete the task in the non-diabetic group $\left(p=0.004, \eta^{2}=0.37\right)$. In the group with type 1 diabetes no significant differences were observed between the two study conditions ( $p=0.44, \eta^{2}=$ $0.045)$. However, the glycaemia $\times$ group interaction was not significant $(p=0.38)$.

Hand steadiness

In the hand steadiness test a significant decrement was seen during hypoglycaemia $\left(p=0.003, \eta^{2}=0.40\right)$ in the nondiabetic group. No such significant decrement during hypoglycaemia was demonstrable in the type 1 diabetic patients $\left(p=0.11, \eta^{2}=0.18\right)$. The glycaemia $\times$ group interaction achieved statistical significance, suggesting that the effects of hypoglycaemia differed significantly between the groups $(p=0.021)$.

\section{Tracing time}

No significant change in performance was observed in tracing time between the two study conditions, either in the non-diabetic group $\left(p=0.480, \eta^{2}=0.030\right)$ or in the group with type 1 diabetes $\left(p=0.39, \eta^{2}=0.06\right)$. However, nonsignificant differences were noted with tracing time errors in participants with $\left(p=0.50, \eta^{2}=0.03\right)$ and without type 1 diabetes $\left(p=0.436, \eta^{2}=0.03\right)$. The glycaemia $\times$ group interaction was not significant for either tracing time $(p=$ $0.62)$ or tracing time errors $(p=0.70)$.

\section{Pursuit rotor}

Mean scores for time on target were significantly greater during euglycaemia than during hypoglycaemia in the non-

Table 1 Results of tests of psychomotor function during euglycaemia and hypoglycaemia in 20 non-diabetic volunteers and 16 people with type 1 diabetes

\begin{tabular}{|c|c|c|c|c|c|c|c|c|c|c|}
\hline \multirow[t]{2}{*}{ Variable } & \multicolumn{4}{|l|}{ Non-diabetic } & \multicolumn{4}{|c|}{ Type 1 diabetes } & \multicolumn{2}{|c|}{$\begin{array}{l}\text { Glycaemia } \times \\
\text { group interaction }\end{array}$} \\
\hline & Euglycaemia & Hypoglycaemia & $\begin{array}{l}p \\
\text { value }\end{array}$ & $\eta^{2}$ & Euglycaemia & Hypoglycaemia & $\begin{array}{l}p \\
\text { value }\end{array}$ & $\eta^{2}$ & $p$ value & $\eta^{2}$ \\
\hline 4CRT (ms) & $576(67)$ & $616(52)$ & 0.008 & 0.364 & $644(10.0)$ & 687 (13) & 0.023 & 0.340 & 0.762 & 0.003 \\
\hline $\begin{array}{l}\text { Grooved } \\
\text { pegboard }\end{array}$ & $63.5(9.0)$ & $70.8(8.6)$ & 0.004 & 0.371 & $69.7(13.5)$ & $72.2(12.4)$ & 0.443 & 0.045 & 0.376 & 0.025 \\
\hline Hand-grip (kg) & $36.6(8.9)$ & $36.5(9.3)$ & 0.897 & 0.001 & 40.8 (11.5) & 39.4 (11.4) & 0.961 & 0.000 & 0.902 & 0.000 \\
\hline Hand steadiness & $91.8(52.3)$ & $179.4(115.7)$ & 0.003 & 0.404 & $108.5(39.4)$ & $125.3(22.8)$ & 0.111 & 0.183 & 0.021 & 0.159 \\
\hline Tracing time (s) & $64.1(15.1)$ & $62.1(11.7)$ & 0.480 & 0.030 & $62.0(12.2)$ & $61.7(13.6)$ & 0.391 & 0.057 & 0.615 & 0.009 \\
\hline $\begin{array}{l}\text { Tracing time } \\
\text { errors }\end{array}$ & $11.3(9.5)$ & $12.6(8.6)$ & 0.436 & 0.034 & $16.6(8.4)$ & $19.1(21.0)$ & 0.504 & 0.035 & 0.702 & 0.005 \\
\hline Pursuit rotor (s) & $25.1(6.8)$ & $21.8(9.6)$ & 0.018 & 0.288 & $27.5(10.5)$ & $21.1(10.2)$ & 0.045 & 0.274 & 0.588 & 0.010 \\
\hline $\begin{array}{l}\text { Static balance } \\
\text { eyes open }(\mathrm{m})\end{array}$ & $0.34(0.12)$ & $0.44(0.17)$ & 0.004 & 0.414 & $0.39(0.09)$ & $0.40(0.08)$ & 0.337 & 0.077 & 0.042 & 0.184 \\
\hline
\end{tabular}

Values are mean (SD)

$4 C R T$ four-choice reaction time test 
diabetic $\left(p=0.018, \eta^{2}=0.29\right)$ and type 1 diabetes $(p=0.04$, $\left.\eta^{2}=0.27\right)$ groups. The glycaemia $\times$ group interaction was not significant $(p=0.59)$.

\section{Static balance}

In the non-diabetic group, total body sway, assessed by static posturography, increased during hypoglycaemia ( $p=$ $0.004, \eta^{2}=0.41$ ). No significant change in total body sway was observed in the group with type 1 diabetes $(p=0.34$, $\left.\eta^{2}=0.08\right)$. The glycaemia $\times$ group interaction achieved statistical significance, suggesting that the effects of hypoglycaemia differed significantly between the groups $(p=0.042)$.

\section{Hand grip}

No significant deterioration of grip strength was observed during hypoglycaemia compared with euglycaemia in either group (non-diabetic group: $p=0.90, \eta^{2}=0.001$; type 1 diabetes: $\left.p=0.96, \eta^{2}=0.000\right)$. The glycaemia $\times$ group interaction was not significant $(p=0.90)$.

\section{Discussion}

In the present study hypoglycaemia appeared to exert a different effect between the groups with regard to certain psychomotor tests (static balance and hand steadiness). The deterioration in performance in the Digit Symbol test in both groups during hypoglycaemia confirmed that blood glucose was sufficiently low to impair cognitive function, while all participants experienced symptoms of hypoglycaemia during the study.

In both groups, however, some cognitive tests, including the line tracing and hand-grip tests, were not affected by the moderate degree of hypoglycaemia. The hand-grip strength test is a simple, non-invasive measure of upper extremity muscle strength. The lack of an effect of hypoglycaemia on hand-grip function is consistent with a previous study, which demonstrated that hypoglycaemia had no effect on the peripheral nervous system [26]. Tracing time was also not affected by moderate hypoglycaemia. The effects of hypoglycaemia on spatial ability have not been assessed previously; hence this test may not be suitable for inclusion in a standard neuropsychological test battery to assess the effects of hypoglycaemia on psychomotor function.

Only in two of the tests, the four-choice reaction time and pursuit rotor tests, were scores significantly affected by hypoglycaemia in both groups. The effect sizes obtained for the euglycaemia-hypoglycaemia comparison in the two studies showed almost identical effect sizes (four-choice reaction time, $\eta^{2}=0.36$ vs $\eta^{2}=0.34$ in controls vs type 1 diabetic participants; pursuit rotor, $\eta^{2}=0.29$ vs $\eta^{2}=0.27$ in non-diabetic vs type 1 diabetic participants). Previous research has demonstrated that recurrent exposure to hypoglycaemia can lead to preservation of cognitive function with regard to certain cognitive domains [27]. Choice reaction time, however, does not appear to adapt, and if hypoglycaemia is induced slowly, it deteriorates at similar levels of blood glucose in most groups of participants, irrespective of their previous glycaemic experience or state of hypoglycaemia awareness [28]. Given that no difference was observed in pursuit rotor results between the groups, it seems possible that pursuit rotor also does not adapt to recurrent hypoglycaemia.

The following tests, namely hand steadiness, total body sway and pursuit rotor, revealed disparate results between the groups. All of the results for these tests were significantly affected by hypoglycaemia in the non-diabetic group, with none being significantly affected in the group with type 1 diabetes. This would appear to suggest that type 1 diabetic patients are less affected by hypoglycaemia than healthy volunteers. However, to conclude that the effects of hypoglycaemia are significantly different between the two groups, it is necessary to do more than simply demonstrating that effects are significant in one group and not the other. Thus application of a rigorous statistical method to test for any differences between the groups would have to generate a significant interaction between group status and glycaemic condition. Indeed, for two of the three tests (hand steadiness and total body coordination [sway]), such a significant interaction was seen. This study therefore provides further evidence that a significant difference is exerted by hypoglycaemia when non-diabetic volunteers are compared with type 1 diabetic patients. The mechanism behind this differing effect of hypoglycaemia on psychomotor function remains unknown. However, it may relate to the difference in sympathoadrenal activation between the groups, a behavioural advantage of type 1 diabetic over non-diabetic participants, which is derived from previous exposure to hypoglycaemia or possibly through hypoglycaemia-induced cerebral adaptation

Hypoglycaemia is known to result in activation of the autonomic nervous system with subsequent release of counter-regulatory hormones. Recurrent exposure to hypoglycaemia (as would be expected in the group with type 1 diabetes) attenuates this response. The endogenous effects of autonomic activation, which are manifested by sweating, shaking and a pounding heart, could therefore potentially interfere with psychomotor functions such as hand-eye coordination and fine motor control. Therefore it is possible that the differences in scores for the pursuit rotor and hand steadiness tests may reflect the differing catecholamine responses to hypoglycaemia that were observed between the groups. However, the autonomic features result from 
central autonomic neural activation (via hypothalamic centres) [29] and, whereas the rise in plasma catecholamines augments the intensity of some autonomic manifestations such as a pounding heart and tremor, it is not the principal mediator. No significant correlations were demonstrable in the present study between plasma concentrations of catecholamines and a test of fine motor control (hand steadiness). However, the effect sizes were modest and a larger study would be required to investigate this possibility further. Inevitably, the present study, though very powerful for the principal within-participants analyses, provided less statistical power for correlational analyses.

In non-diabetic volunteers and in people with type 1 diabetes, antecedent hypoglycaemia can alter the glycaemic thresholds for symptomatic and counter-regulatory hormonal responses, re-setting these at lower blood glucose levels. In a small study of adults with type 1 diabetes $(n=6)$, twiceweekly episodes of experimentally induced hypoglycaemia over 1 month resulted in preservation of cognitive function (pattern recognition, memory, attention and information processing) [27]. While animal experiments have suggested that improved glucose uptake via glucose transporters may contribute to the cerebral adaptation associated with recurrent hypoglycaemia [30] in humans, it is not known whether regional brain differences in these processes might underlie differential adaptation of neurocognitive brain functions to recurrent hypoglycaemia [30].

Another potential explanation is that, in the type 1 diabetes group, previous experience of coping with the effects of hypoglycaemia may confer a behavioural advantage over the non-diabetic group. Direct observation of the participants with type 1 diabetes during administration of the cognitive function tests gave the impression that they were concentrating on the tasks during hypoglycaemia with greater intensity than the hypoglycaemia-naïve, non-diabetic participants. A previous clamp study, conducted by our group, of 16 type 1 diabetic adults who had normal awareness of hypoglycaemia found no difference between participants in their perception of their ability to concentrate during the conditions of hypoglycaemia $(2.5 \mathrm{mmol} / \mathrm{l})$ and euglycaemia $(4.5 \mathrm{mmol} / \mathrm{l})$ [31]. The question of whether there really is a difference in ability to concentrate during hypoglycaemia between people with type 1 diabetes and hypoglycaemia-naïve, non-diabetic participants remains to be explored.

Participants of both sexes participated in the present study. Sex-related differences have been observed previously in the counter-regulatory hormonal responses to hypoglycaemia [32-36], but the symptomatic responses do not differ [37]. The evidence for a sex-related difference in degree of cognitive impairment is equivocal. In one study of non-diabetic young adults, cognitive impairment was less pronounced in women than in men in tests of selective and sustained attention and mental flexibility [38], while in a different study, this cognitive advantage in women was observed only at very mild hypoglycaemia, with no difference when blood glucose was lowered to $2.6 \mathrm{mmol} / 1$ [39]. While we cannot exclude a sex-related difference in the effect of hypoglycaemia on psychomotor function, this is unlikely to be substantial at the degree of hypoglycaemia tested.

Caution should, however, be exercised before concluding that the effects of hypoglycaemia differed significantly between the two groups. While the size of the groups in the present study was well powered to examine the effect of hypoglycaemia within these groups, statistical power was insufficient for formal between-group comparisons. Given the effect sizes observed, more than 60 participants per group would be required to have high power to detect a medium effect. This would be very hard to implement in studies of this nature. However, despite these reservations, the participants with type 1 diabetes who had normal awareness of hypoglycaemia appeared to be relatively resistant to the effects of hypoglycaemia on many aspects of psychomotor function.

In conclusion, the present study has demonstrated that moderate acute insulin-induced hypoglycaemia exerted a different effect on responses to certain tests of psychomotor function in the two groups. The difference in response to hypoglycaemia between our healthy volunteers and type 1 diabetic participants was in some part unexpected and thus warrants further investigation using positron emission tomography or functional magnetic resonance imaging to demonstrate differences in activation/deactivation levels during hypoglycaemia.

Acknowledgement J. Geddes was supported by a research grant (CZB/4/423) from the Scottish Executive, Health Department, Chief Scientist Office. Equipment was purchased with support of the Borland Trust. I. J. Deary is the recipient of a Royal Society-Wolfson Research Merit Award.

Duality of interest B. M. Frier has been a member of advisory panels for, and has received honoraria/consulting fees from Eli Lilly, Novo Nordisk, Sanofi-Aventis, GlaxoSmithKline and Takeda. Otherwise, the authors declare that there is no duality of interest associated with this manuscript.

\section{References}

1. Deary IJ, Hepburn DA, MacLeod KM, Frier BM (1993) Partitioning the symptoms of hypoglycaemia using multi-sample confirmatory factor analysis. Diabetologia 36:771-777

2. Deary IJ (1993) Neuropsychological manifestations. In: Frier BM, Fisher BM (eds) Hypoglycaemia and diabetes: clinical and physiological aspects. Edward Arnold, London, pp 337-346

3. Deary IJ (2007) Symptoms of hypoglycaemia and effects on mental performance and emotions. In: Frier BM, Fisher M (eds) 
Hypoglycaemia in clinical diabetes. 2nd edn. Wiley, Chichester, pp $25-48$

4. Hoffman RG, Speelman DJ, Hinnen DA, Conley KL, Guthrie RA, Knapp RK (1989) Changes in cortical functioning with acute hypoglycemia and hyperglycemia in type 1 diabetes. Diabetes Care 12:193-197

5. Mitrakou A, Ryan C, Veneman T et al (1991) Hierarchy of glycemic thresholds for counterregulatory hormone secretion, symptoms, and cerebral dysfunction. Am J Physiol 260:E67-E74

6. Widom B, Simonson DJ (1990) Glycemic control and neuropsychologic function during hypoglycemia in patients with insulin-dependent diabetes mellitus. Ann Intern Med 112:904-912

7. Wirsen A, Tallroth G, Lindgren M, Agardh C (1992) Neuropsychological performance differs between type 1 diabetic and normal men during insulin-induced hypoglycaemia. Diabet Med 9:156-165

8. Ziegler D, Hubinger A, Muhlen H, Gries FA (1992) Effects of previous glycaemic control on the onset and magnitude of cognitive dysfunction during hypoglycaemia in type 1 (insulindependent) diabetic patients. Diabetologia 35:828-834

9. Gold AE, Deary IJ, MacLeod KM, Frier BM (1995) The effect of IQ level on the cognitive deterioration experienced during acute hypoglycaemia in normal humans. Intelligence 20:267-290

10. McAulay V, Ferguson SC, Deary IJ, Frier BM (2001) Acute hypoglycemia in humans causes attentional dysfunction while non-verbal intelligence is preserved. Diabetes Care 24:1745-1750

11. Sommerfield AJ, Deary IJ, McAulay V, Frier BM (2003) Moderate hypoglycemia impairs multiple memory functions in healthy adults. Neuropsychology 17:125-132

12. Sommerfield AJ, Deary IJ, McAulay V, Frier BM (2003) Shortterm, delayed, and working memory are impaired during hypoglycemia in individuals with type 1 diabetes. Diabetes Care 26:390-396

13. Deary IJ, Sommerfield AJ, McAulay V, Frier BM (2003) Moderate hypoglycaemia obliterates working memory in humans with and without insulin-treated diabetes. J Neurol Neurosurg Psychiatry 74:278-279

14. Warren RE, Allen KA, Sommerfield AJ, Deary IJ, Frier BM (2004) Acute hypoglycemia impairs non-verbal intelligence. Diabetes Care 27:1447-1448

15. Schachinger H, Cox D, Linder L, Brody S, Keller U (2003) Cognitive and psychomotor function in hypoglycemia: response error patterns and retest reliability. Pharmacol Biochem Behav 75:915-920

16. Stevens AB, McKane WR, Bell PM, Bell P, King DJ, Hayes JR (1989) Psychomotor performance and counterregulatory responses during mild hypoglycemia in healthy volunteers. Diabetes Care 12:12-17

17. Lingenfelser T, Overkamp D, Renn W et al (1992) Cognitive and psychomotor function during severe insulin-induced hypoglycaemia in insulin-dependent diabetic patients. Neuropsychobiology 25:161-165

18. Ferguson SC, Blane A, Perros P et al (2003) Cognitive ability and brain structure in type 1 diabetes: relation to microangiopathy and preceding severe hypoglycemia. Diabetes 52:149-156

19. Gold AE, MacLeod KM, Frier BM (1994) Frequency of severe hypoglycemia in patients with type 1 diabetes with impaired awareness of hypoglycemia. Diabetes Care 17:697-703

20. De Fronzo R, Tobin JD, Andres R (1979) Glucose clamp technique: a method for quantifying insulin secretion and resistance. Am J Physiol 273:E214-E223
21. Abumrad NN, Rabin D, Diamond MP, Lacy WW (1981) Use of a heated superficial hand vein as an alternative site for the measurement of amino acid concentrations and for the study of glucose and alanine kinetics in man. Metabolism 30:936-940

22. Deary IJ, Der G, Ford G (2001) Reaction times and intelligence differences: a population-based cohort study. Intelligence 29:389-399

23. Matthews GC, Kløve H (1964) Instruction manual for the adult neuropsychology test battery Grooved Pegboard Test. University of Wisconsin Medical School, Madison, pp 59-60

24. Cameron E, Sinclair W, Tiplady B (2001) Validity and sensitivity of a pen computer battery of performance tests. J Psychopharmacol 15:105-110

25. Colledge NR, Cantley P, Peaston I, Brash H, Lewis S, Wilson JA (1994) Ageing and balance: the measurement of spontaneous sway by posturography. Gerontology 40:273-278

26. Strachan MWJ, Deary IJ, Ewing FME, Ferguson SC, Young MJ, Frier BM (2000) Acute hypoglycemia impairs the function of the central but not the peripheral nervous system. Physiol Behav 72:83-92

27. Ovalle F, Fanelli CG, Paramore DS, Hershey T, Craft S, Cryer PE (1998) Brief twice-weekly episodes of hypoglycemia reduce detection of clinical hypoglycemia in type 1 diabetes mellitus. Diabetes 47:1472-1479

28. Maran A, Lomas J, Macdonald IA, Amiel SA (1995) Lack of preservation of higher brain function during hypoglycaemia in patients with intensively treated IDDM. Diabetologia 38:1412-1418

29. Benzo CA (1983) The hypothalamus and blood glucose regulation. Life Sciences 32:2509-2515

30. Schultes B, Kern W, Oltmanns K et al (2005) Differential adaptation of neurocognitive brain functions to recurrent hypoglycemia in healthy men. Psychoneuroendocrinology 30:149-161

31. McAulay V, Deary IJ, Sommerfield AJ, Matthews G, Frier BM (2006) Effects of acute hypoglycemia on motivation and cognitive interference in people with type 1 diabetes. J Clin Psychopharmacol 26:143-151

32. Amiel S, Maran A, Powne J, Umpleby A, Macdonald L (1993) Gender differences in counterregulation to hypoglycaemia. Diabetologia 36:460-464

33. Davis SN, Cherrington AD, Goldstein R, Jacobs J, Price L (1993) Effects of insulin on the counterregulatory response to equivalent hypoglycemia in normal females. Am J Physiol 265:E680-E689

34. Diamond M, Jones T, Caprio S et al (1993) Gender influences counterregulatory hormone responses to hypoglycemia. Metabolism 142:1568-1572

35. Johnston M, Bower M, Seckl J, Lightman S (1990) Neurohypophysial secretion to insulin induced hypoglycaemia and its regulation by endogenous opioids in women. Acta Endocrinol 122:467-471

36. Davis SN, Fowler S, Costa F (2000) Hypoglycemic counterregulatory responses differ between men and women with type 1 diabetes. Diabetes 49:65-72

37. Geddes J, Warren RE, Sommerfield AJ et al (2006) Absence of sexual dimorphism in the symptomatic response to hypoglycemia in adults with and without type 1 diabetes. Diabetes Care 29:1667-1669

38. Draelos MT, Jacobson AM, Weinger K et al (1995) Cognitive function in patients with insulin-dependent diabetes mellitus during hyperglycemia and hypoglycemia. Am J Med 98:135145

39. Gonder-Frederick LA, Cox DJ, Driesen NR, Ryan CM, Clarke WL (1994) Individual differences in neurobehavioral disruption during mild and moderate hypoglycemia in adults with IDDM. Diabetes 43:1407-1412 